\title{
PERAN ENTREPRENEURIAL ORIENTATION TERHADAP KINERJA PERUSAHAAN MELALUI TOTAL QUALITY MANAGEMENT (STUDI DI PERUSAHAAN MEBEL PT KAYAN JAYA TANJUNG)
}

\author{
THE ROLE OF ENTREPRENEURIAL ORIENTATION ON FIRM PERFORMANCE THROUGH TOTAL \\ QUALITY MANAGEMENT (STUDY IN FURNITURE COMPANY PT KAYAN JAYA TANJUNG)
}

\section{Timotius FCW Sutrisno*), Gladys G Gosal"), Richard Surya*)}

\author{
*) Program Studi Manajemen, Universitas Ciputra Surabaya \\ CitraLand CBD Boulevard, Made, Sambikerep, Surabaya City, Jawa Timur 67219, Indonesia
}

\begin{abstract}
The application of the concept of Total Quality Management (TQM) is expected to be able to assist companies in responding to consumer needs in the future. This research aims to see the mediating effect of Total Quality Management on Entrepreneurial Orientation with Firm Performance. To support this theory, this study takes data from the furniture company PT Kayan Jaya Tanjung, Surabaya. This study was analyzed using the partial least square method by using 78 workers at PT Kayan Jaya Tanjung with a minimum level of manager. Respondents were drawn based on two branch factories, namely PT Kayan Jaya Tanjung I and PT Kayan Jaya Tanjung II. The results of this study indicate that the company can gather its human resources (TQM) to formulate a proactive strategy to anticipate future customer demand (EO) so that companies can maintain the quality of their products (firm performance). This study shows that applying the concept of TQM with a good entrepreneurial orientation will form a sustainable strategy to achieve a competitive advantage for company performance.
\end{abstract}

Keywords: competitive advantage, entrepreneurial orientation, furniture, total quality management, firm performance

\begin{abstract}
Abstrak: Penerapan konsep Total Quality Management (TQM) diharapkan dapat membantu perusahaan dalam menjawab kebutuhan konsumen di masa mendatang. Penelitian ini bertujuan melihat pengaruh mediasi Total Quality Management terhadap Entrepreneurial Orientation dengan kinerja perusahaan. Untuk mendukung teori tersebut, penelitian ini mengambil data dari perusahaan furniture PT Kayan Jaya Tanjung, Surabaya. Penelitian ini dianalisis menggunakan metode Partial Least Square dengan menggunakan 78 pekerja di PT Kayan Jaya Tanjung dengan level minimal manajer. Responden diambil berdasarkan dua pabrik cabang, yaitu PT Kayan Jaya Tanjung I dan PT Kayan Jaya Tanjung II. Hasil penelitian ini menunjukkan bahwa perusahaan dapat mengumpulkan sumber daya manusia (TQM) untuk merumuskan strategi proaktif dalam mengantisipasi permintaan pelanggan (EO) di masa mendatang sehingga perusahaan dapat menjaga kualitas produknya (kinerja perusahaan). Penelitian ini menunjukkan bahwa penerapan konsep TQM dengan orientasi kewirausahaan yang baik membentuk strategi yang berkelanjutan untuk mencapai keunggulan bersaing bagi kinerja perusahaan.
\end{abstract}

Kata kunci: keunggulan bersaing, entrepreneurial orientation, furniture, total quality management, kinerja perusahaan

\footnotetext{
${ }^{1}$ Corresponding author:

Email: timotius.febry@ciputra.ac.id
} 


\section{PENDAHULUAN}

Produktivitas kayu di Indonesia telah mengalami peningkatan sejak tahun 2017 (BPS, 2019). Hal ini membuat perkembangan industri kayu di Indonesia dapat menjadi sorotan dalam dunia bisnis. Namun, tahun 2020 merupakan tahun yang memberikan warna berbeda bagi dunia bisnis. Masuknya wabah COVID19 ke Indonesia pada kuartal I tahun 2020 membuat semua sektor industri termasuk industri manufaktur di Indonesia menjadi menurun (BPS, 2020). Untuk mengatasi permasalahan tersebut, perusahaan membutuhkan sebuah strategi baru bagi manajemen perusahaan dapat mencapai keunggulan kompetitif. Banyak perusahaan berusaha mencari alternatif cara dalam meningkatkan nilai dari produk dengan strategi dan kualitas yang baik. Hal ini disebabkan oleh kondisi lingkungan bisnis yang dinamis. Kewirausahaan menjadi penting dikarenakan dampak yang ditimbulkan terhadap kinerja organisasi sangat positif untuk dapat mencapai keunggulan kompetitif (Sahoo dan Yadav, 2017).

Kewirausahaan memiliki fungsi untuk mengelola proses produksi dengan praktek inovatif dan memanfaatkan teknologi untuk menciptakan suatu hal yang baru bagi perusahaan (Zehir et al. 2015). Oleh karena itu, Entrepreneurial Orientation (EO) merupakan sebuah konsep yang tepat bagi suatu perusahaan karena EO mengacu pada strategy orientation, gaya pengambilan suatu keputusan, praktik dan metodenya (Sahoo dan Yadav, 2017). Selain itu, hubungan antara strategi (dan EO khususnya) dan berbagai hasil organisasi bersifat spesifik konteks, yaitu bergantung pada faktor lingkungan dan organisasi (Vaznyte, 2019).

Dalam EO terdapat pemikiran proses pembuatan strategi yang dapat diwujudkan dalam kegiatan operasional suatu perusahaan yang memengaruhi keberhasilan wirausaha (Gupta dan Batra, 2016; Teofilus et al. 2020). Keberhasilan wirausaha tergantung pada tindakan, komitmen, sikap, dan pengetahuan dalam memahami kualitas ketika praktik. Kualitas ketika praktik tersebut seringkali disebut sebagai "perjalanan" dengan keyakinan bahwa dalam pelaksanaan yang tepat, suatu mutu sistem akan membuat hasil yang bermanfaat dalam kinerja bisnis jangka panjang (Sahoo dan Yadav, 2017). Untuk menguji kualitas suatu perusahaan tersebut, dapat menggunakan sebuah konsep strategi yaitu TQM (Total Quality Management).
TQMmerupakan sebuah strategidalamsuatumanajemen yang bertujuan untuk meningkatkan kualitas performa perusahaan. Kualitas performa perusahaan dapat diukur dari kepuasan pelanggan perusahaan itu sendiri. Saleh et al. (2018) menemukan dalam praktik nya, TQM termasuk perencanaan strategis yang memiliki pengaruh yang besar terhadap performa perusahaan dalam hal menghitung keuntungan dan produktivitas perusahaan. Pemanfaatan TQM merupakan salah satu langkah bagi pemimpin perusahaan untuk mengukur risiko dalam efisiensi kinerja dalam perusahaan. Hal ini sesuai dengan salah satu nilai dari entrepreneurial spirit yaitu calculated risk taking.

Penelitian ini menerapkan grand teori Resourced Based View (RBV). Teori RBV memandang suatu perusahaan yang memiliki kinerja dan kualitas sumber daya yang baik akan memiliki keunggulan kompetitif dalam bersaing (Sutrisno, 2019). Namun, tidak semua sumber daya yang dimiliki perusahaan dapat berpotensi untuk mencapai keunggulan kompetitif. Sumber daya yang dimiliki perusahaan harus memiliki aspek: (a) bernilai lebih, (b) tidak dapat ditiru oleh pesaing, dan (c) tidak dapat digantikan dengan sumber daya lainnya (Barney, 1991). EO dapat dianggap sebagai aset tidak berwujud perusahaan yang dapat dikembangkan oleh sumber daya internal perusahaan (Vaitoonkiat dan Charoensukmongkol, 2020).

Penerapan EO dinilai mampu menjadi konsep utama dalam perusahaan yang terdiri dari berbagai nilai kedisiplinan termasuk nilai entrepreneurship dan operasional perusahaan (Vaitoonkiat dan Charoensukmongkol, 2020). EO memungkinkan perusahaan untuk mengeksplor peluang pasar yang lebih besar, proaktif dalam menunjukkan ide-ide yang inovatif, dan mengambil langkah yang agresif dalam menghadapi pesaingnya. Pandangan terkait entrepreneurial juga dikatakan sebagai sebuah usaha untuk mengoptimalkan sumber daya yang ada guna dapat meraih hasil yang terbaik. Hal ini dilakukan dengan improvisasi yang dilakukan secara terus menerus dan melakukan rekonfigurasi sumber daya secara berkesinambungan (Utami, 2019). Rezaei dan Ortt (2018) juga menunjukkan bahwa EO memiliki dampak yang positif bagi kinerja perusahaan dalam konteks pasar atau jenis perusahaan tertentu seperti industri manufaktur. Kinerja perusahaan dapat dilihat dari cara operasional perusahaan bekerja dengan baik. Bagi manajer, menilai kinerja perusahaan sangatlah penting berkaitan dengan memahami aspek internal dari 
perusahaan agar dapat menjadi perusahaan yang lebih entrepreneurial. Studi ini ingin melihat bahwa EO dan TQM merupakan dua aspek yang tidak terpisahkan, mengingat TQM tanpa diikuti dengan EO tidak akan berfungsi secara optimal, begitu juga sebaliknya. Sehingga dalam ruang lingkup operasional, performa sebuah organisasi akan sangat tergantung dari EO dan TQM.

Dalam penerapannya, EO dan TQM merupakan kombinasi strategi yang sangat penting bagi perusahaan untuk mencapai keunggulan kompetitif (Sutrisno et al. 2019). EO memiliki fokus pada perancangan strategi yang mendukung kegiatan berwirausaha dalam mengambil suatu keputusan, praktik, maupun metode (Sahoo dan Yadav, 2017). Penerapan EO dapat memicu sumber daya manusia dalam suatu perusahaan untuk mengembangkan proses pemikiran maupun pembuatan strategi yang diwujudkan dalam kegiatan operasional yang dapat memengaruhi keberhasilan wirausaha (Gupta dan Batra, 2016). EO dan TQM dapat dianggap sebagai sumber daya tidak berwujud yang bertujuan untuk membawa perusahaan berhasil dalam bersaing. Penerapan konsep TQM tidak akan berjalan dengan baik tanpa adanya penerapan EO pada setiap level dari manajemen perusahaan (Teofilus et al. 2020). Hal itu menunjukkan bahwa EO dan TQM merupakan dua hal yang tidak dapat dipisahkan untuk membangun performa perusahaan yang stabil. EO dan TQM perlu dihubungkan sebagai subjek pada penelitian.

TQM telah diartikan sebagai metode pendekatan holistik dan filosofi manajemen dalam mencari perbaikan sistem manajemen perusahaan untuk menghasilkan produk atau layanan yang dapat memenuhi harapan pelanggan. Temuan penelitian Salisu (2019) menjelaskan bahwa terdapat kontribusi manajerial untuk Usaha Kecil Menengah (UKM) di Nigeria dan negara berkembang yang mengarah pada kegiatan investasi dalam mengembangkan kemampuan teknologi, relasional, dan pembelajaran untuk memajukan teknologi operasi untuk daya saing dan kinerja yang lebih baik. Penerapan TQM telah banyak dipakai dalam 50 tahun terakhir oleh banyak perusahaan dan terdapat beragam dukungan yang menjelaskan adanya pengaruh TQM terhadap performa perusahaan. Keberhasilan penerapan TQM bagi perusahaan manufaktur telah banyak memperoleh perhatian bagi perusahaan terutama bagi perusahaan di Kawasan Asia. TQM memiliki pengaruh yang besar bagi performa perusahaan dalam menghitung produktivitas dan keunggulan perusahaan (Sutrisno, 2019; Utami,
2017). Selain itu, TQM mampu untuk membantu para manajer maupun karyawan dalam perusahaan untuk meningkatkan performa dan efektivitas dalam bekerja (Al-Dhaafri et al. 2016).

Penggunaan konsep TQM sebagai mediasi dari EO terhadap performa perusahaan dinilai mampu menjadi salah satu strategi untuk dapat diterapkan. Dalam setiap penerapan strategi pada suatu perusahaan, tentunya harus memperhatikan peluang yang dapat diraih untuk dapat membuat pangsa pasar lebih besar. Namun, hal itu harus dilakukan oleh perusahaan dengan memperhitungkan risiko yang mungkin terjadi. Strategi bisnis yang diadopsi oleh perusahaan memengaruhi penekanan relatif yang dilakukan perusahaan dalam pengembangan kemampuan. Jenis strategi seperti reactor, defender, analyzer, dan prospector dapat memengaruhi peningkatan kemampuan adaptif yang merupakan salah satu jenis kapabilitas dinamis (Pang, 2019). Kebaruan yang ada pada studi ini adalah pembuktian bahwa keterhubungan antara EO dan TQM dalam ruang lingkup industri merupakan dua komponen yang tidak terpisahkan. Perusahaan yang memiliki EO akan lebih mudah untuk mengimplementasikan strategi dengan kualitas yang lebih baik dan sustain. Bila dilihat secara umum, penerapan EO tidak dapat berjalan dengan baik apabila sebuah perusahaan tidak mampu memenuhi harapan pelanggan dengan kualitas dari produk atau layanan yang dihasilkan (Sutrisno et al. 2019; Purwantoro, 2018). Data pada penelitian ini diambil dari karyawan aktif PT Kayan Jaya Tanjung di bidang manajemen pada bagian perusahaan. Penelitian ini bertujuan untuk melihat pengaruh mediasi Total Quality Management terhadap Entrepreneurial Orientation dengan Kinerja Perusahaan.

\section{METODE PENELITIAN}

Untuk menguji model dari hipotesis, penelitian ini menggunakan metode kuantitatif. Data dari penelitian ini diambil dari para pekerja di perusahaan mebel PT Kayan Jaya Tanjung yang bertempat tinggal di kota Surabaya, Indonesia. Data primer pada penelitian ini diambil dari 78 karyawan aktif pada perusahaan PT Kayan Jaya Tanjung di bidang manajemen masingmasing bagian perusahaan. Selanjutnya, dilakukan perhitungan perbandingan jumlah karyawan yang berada di PT Kayan Jaya Tanjung I dan PT Kayan Jaya Tanjung II. Sampel penelitian ini terdiri dari 44 orang dari karyawan PT Kayan Jaya Tanjung I dan 
34 orang pegawai dari PT Kayan Jaya Tanjung II. Sebanyak 78 kuesioner disebarkan pada periode bulan Oktober hingga November 2020 dengan membagikan kuesioner online. Sebanyak 50 kuesioner diterima pada penelitian ini sebagai perwakilan sampel dari kedua cabang perusahaan PT Kayan Jaya Tanjung. Kondisi ini menunjukkan adanya respon rate dalam penelitian ini sebanyak 64\%. Hasil dari responden yang telah didapatkan pada penelitian ini diolah menggunakan perangkat Partial Least Square (PLS).

Skala pengukuran penelitian ini menggunakan skala Likert dengan 7 nilai. Metode pengukuran skala Likert terdiri dari pemberian skor 1-7 pada setiap jawaban responden agar dapat diolah. Ketentuan yang ditetapkan untuk pengukuran skala Likert, yaitu (1) Sangat Tidak Setuju, (2) Tidak Setuju, (3) Agak Tidak Setuju, (4) Netral, (5) Agak Setuju, (6) Setuju, (7) Sangat Setuju. Gambar 1 memperlihatkan model hipotesis Total Quality Management sebagai mediator dari pengaruh Entrepreneurial Orientation terhadap Firm Performance.

Berdasarkan kajian literatur dan latar belakang, penelitian ini mengajukan 4 (empat) hipotesis sebagai berikut:

$\mathrm{H}_{1}$ : Entrepreneurial Orientation berpengaruh signifikan terhadap Total Quality Management.
$\mathrm{H}_{2}$ : Total Quality Management berpengaruh signifikan terhadap Firm Performance.

$\mathrm{H}_{3}$ : Entrepreneurial Orientation berpengaruh signifikan terhadap Firm Performance.

$\mathrm{H}_{4}$ : Total Quality Management memediasi pengaruh Entrepreneurial Orientation terhadap Firm Performance.

\section{HASIL PENELITIAN}

Karakteristik responden dari penelitian ini disajikan dalam Tabel 1 yang terdiri dari beberapa data demografis seperti: usia, jenis kelamin, domisili, dan lama bekerja. Dari 50 sampel, seluruh responden bertempat tinggal di kota Surabaya. Jumlah pekerja yang sudah berumur 30-40 tahun sebanyak 31 orang (62\%), 40-50 tahun sebanyak 17 orang (34\%), serta berada pada usia di atas 50 tahun sebanyak 2 orang (4\%). Hal ini menunjukkan mayoritas pekerja PT Kayan Jaya Tanjung memiliki usia yang cenderung masih muda dan produktif. Berdasarkan 50 orang responden, mayoritas pekerja PT Kayan Jaya Tanjung telah bekerja di kisaran 5-10 tahun sebanyak 32 orang (64\%) yang menunjukkan bahwa rata-rata pekerja memiliki pengalaman yang cukup banyak dalam bidang mebel kayu.

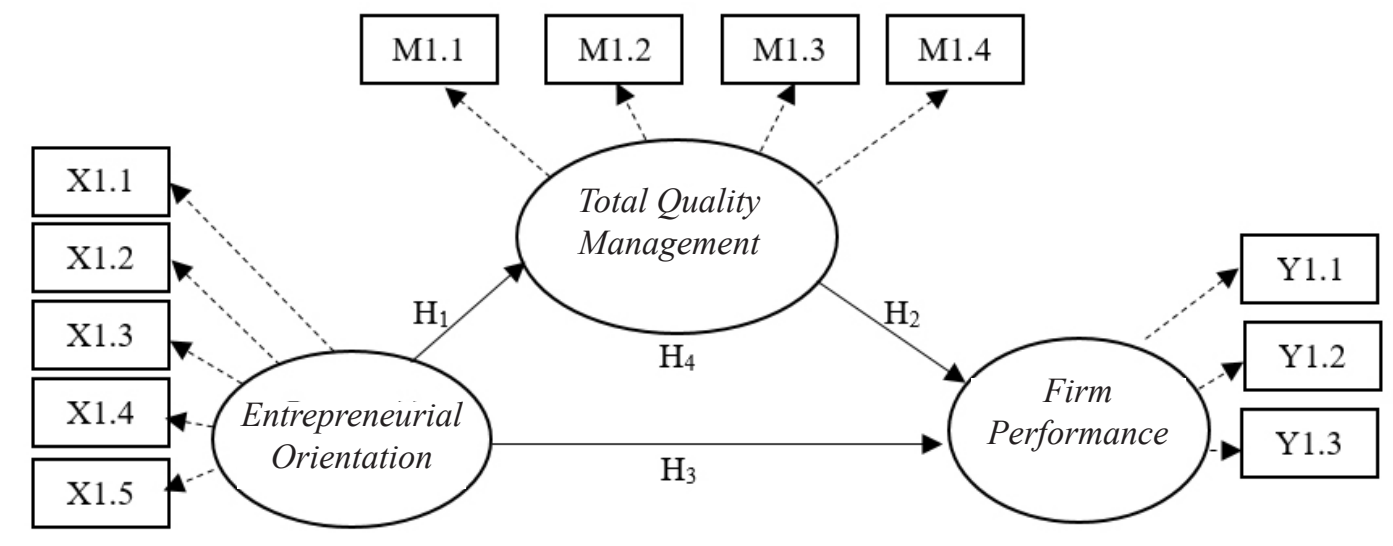

Gambar 1. Model hipotesis Total Quality Management sebagai "mediator" dari pengaruh Entrepreneurial Orientation terhadap Firm Performance. 


\section{Confirmatory Factory Analysis}

Tabel 2 memperlihatkan Confirmatory Factor Analysis, dimana terdapat tiga variabel yang meliputi EntrepreneurialOrientation, TotalQualityManagement, dan Firm Performance. Uji validitas terdiri dari validitas konvergen dan validitas diskriminan. Validitas konvergen merupakan pengukur dari suatu konstruk yang harus berkorelasi tinggi dan dapat dinilai dari loading factor pengukuran dengan konstruknya. Rule of thumb dalam validitas konvergen untuk outer loading $>0,7$ dan average variance extracted $>0,5$. Validitas diskriminan merupakan pengukur dari suatu konstruk harus tidak berkorelasi tinggi dan dapat dinilai dari cross loading pengukur dengan konstruknya. Apabila cross loading variabel diskriminan dalam satu variabel menunjukkan $>0,7$, maka indikator tersebut dikatakan valid. Namun, apabila score loading menunjukkan
$<0,5$ maka indikator tersebut dapat dihapus karena tidak memenuhi rule of thumb yang telah ditetapkan. Jika score loading menunjukkan angka diantara 0,50,7 sebaiknya tidak dihilangkan selama skor average variance extracted $>0,5$ (Sarstedt et al. 2017).

Pada pengujian reliabilitas menggunakan dua metode, yaitu mengukur batas nilai bawah nilai reliablitas (Cronbach's Alpha) dan mengukur nilai reliabilitas sesungguhnya (Composite Reliability). Uji reliabilitas memiliki rule of thumb nilai alpha $>0,7$ (Sarstedt et al. 2017). Tabel 3 menunjukkan kriteria yang dihasilkan dari pengujian menggunakan PLS yaitu dari composite reliability dan Cronbach's alpha pada penelitian ini. Dapat dilihat nilai Composite reliability dan Cronbach's alpha dari masing-masing variabel telah berada $>0,7$, hal ini menunjukkan semua variabel dalam penelitian ini dianggap reliabel.

Tabel 1. Data demografi

\begin{tabular}{lcc}
\hline Karakteristik & Jumlah & Persentase \\
\hline Usia & 31 & $62 \%$ \\
$30-40$ Tahun & 17 & $34 \%$ \\
$40-50$ Tahun & 2 & $4 \%$ \\
$>50$ Tahun & 50 & \\
Total & & \\
Jenis Kelamin & 34 & $68 \%$ \\
Laki-laki & 16 & $32 \%$ \\
Perempuan & 50 & \\
Total & & $6 \%$ \\
Lama Bekerja & 3 & $64 \%$ \\
$1-5$ Tahun & 32 & $30 \%$ \\
$5-10$ Tahun & 15 & \\
$>10$ Tahun & 50 & \\
Total & & \\
\hline
\end{tabular}

Tabel 2. Confirmatory Factor Analysis

\begin{tabular}{llc}
\hline Variabel & Indikator & Factor Loading \\
\hline Entrepreneurial Orientation (X) & Innovativeness & 0,801 \\
& Proactiveness & 0,818 \\
& Risk Taking & 0,798 \\
& Competitive aggressiveness & 0,787 \\
& Autonomy & 0,840 \\
Total Quality Management (M) & Cross functional product & 0,742 \\
& Process Quality Management & 0,867 \\
& Quality Empowerment & 0,670 \\
& Organization wide employee training & 0,805 \\
& Design Performance & 0,767 \\
\hline \hline
\end{tabular}


Tabel 3 menunjukkan bahwa nilai Average Variance Extracted (AVE) dari setiap variabel sudah memenuhi syarat rule of thumb, yaitu $>0,5$ sehingga semua indikator dinyatakan valid untuk mengukur variabel dalam penelitian ini meskipun terdapat indikator yang berada $<0,7$. Tabel 3 juga menunjukkan nilai $R$ Square variabel Firm Performance (Y) sebesar 0,604 dan variabel Total Quality Management (M) sebesar 0,601. Variabel Firm Performance dapat dijelaskan sebesar 0,604 (60,4\%) oleh variabel Entrepreneurial Orientation dan Total Quality Management, sedangkan sisanya 39,6\% dijelaskan oleh variabel lain di luar penelitian ini. Variabel Total Quality Management dapat dijelaskan sebesar $0,601(60,1 \%)$ oleh variabel Firm Performance dan sisanya 39,9\% dijelaskan oleh variabel lain di luar penelitian ini. Selanjutnya uji efek mediasi pada penelitian ini menggunakan hasil dari perhitungan dari nilai $\mathrm{P}$ Values dalam indirect effect. Tabel 4 menunjukkan hasil uji efek mediasi bahwa Total Quality Management memiliki pengaruh mediasi partial dikarenakan adanya pengaruh yang signifikan antara variabel $\mathrm{X}$ dan variabel $\mathrm{Y}$. Tabel 4 juga memperlihatkan uji hipotesis dimana seluruh research hipotesis dinyatakan mendukung penelitian. Selanjutnya, Gambar 2 memperlihatkan Partial Least Square Model yang sudah disertai dengan hasil perhitungan masing-masing variabel.
Hasil penelitian menunjukkan pengaruh Entrepreneurial Orientation (X) terhadap Total Quality Management (M) pada pengujian inner model dengan nilai $t$-statistic 13,138 dan $P$ Values 0,000 (t-statistic $>1,96, p$ values $<0,05)$. Hal itu membuktikan bahwa $\mathrm{H}_{1}$ "Entrepreneurial Orientation berpengaruh terhadap Total Quality Management" diterima. Hasil penelitian ini selaras dengan penelitian dari Sutrisno et al. (2019) yang mengatakan adanya pengaruh signifikan antara EO dan TQM. EO dan TQM dilihat sebagai strategi berorientasi yang memiliki kualitas dalam membuat perusahaan berkembang. Sehingga, penerapan EO dan TQM dinilai mampu berdampak baik bagi perusahaan. Perusahaan dengan EO yang baik cenderung mampu mengeksplor pangsa pasar lebih baik. Namun, hal itu dapat terjadi apabila perusahaan mampu mengolah sumber daya manusia nya untuk dapat merencanakan strategi yang proaktif dan inovatif untuk menjadi pionir dalam mengimplementasikannya. Dalam prakteknya, perusahaan harus mampu mengimplementasikan strategi dalam mengejar goal untuk melihat peluang baru dalam pangsa pasarnya. Berdasarkan hal itu, perusahaan yang memiliki EO cenderung memiliki kualitas yang tinggi dalam Menyusun strategi inovatif dan sustainable.

Tabel 3. Model Reliability dan Validity

\begin{tabular}{lllcc}
\hline Variabel & Cronbach's Alpha & AVE & Composite Reliability & $R$ Square \\
\hline X1 & 0,869 & 0,654 & 0,904 & \\
Y1 & 0,790 & 0,707 & 0,878 & 0,604 \\
M1 & 0,776 & 0,600 & 0,856 & 0,601 \\
\hline
\end{tabular}

Tabel 4. Uji Hipotesis

\begin{tabular}{llccc}
\hline Research Hypothesis & Hipotesis & P Values & T Statistic & Keterangan \\
\hline RH1 & EO-FP & 0,019 & 2,349 & Mendukung \\
RH2 & EO-TQM & 0,000 & 13,138 & Mendukung \\
RH3 & TQM-FP & 0,014 & 2,472 & Mendukung \\
RH4 & EO-TQM-FP & 0,020 & 2,329 & Mendukung \\
\hline
\end{tabular}




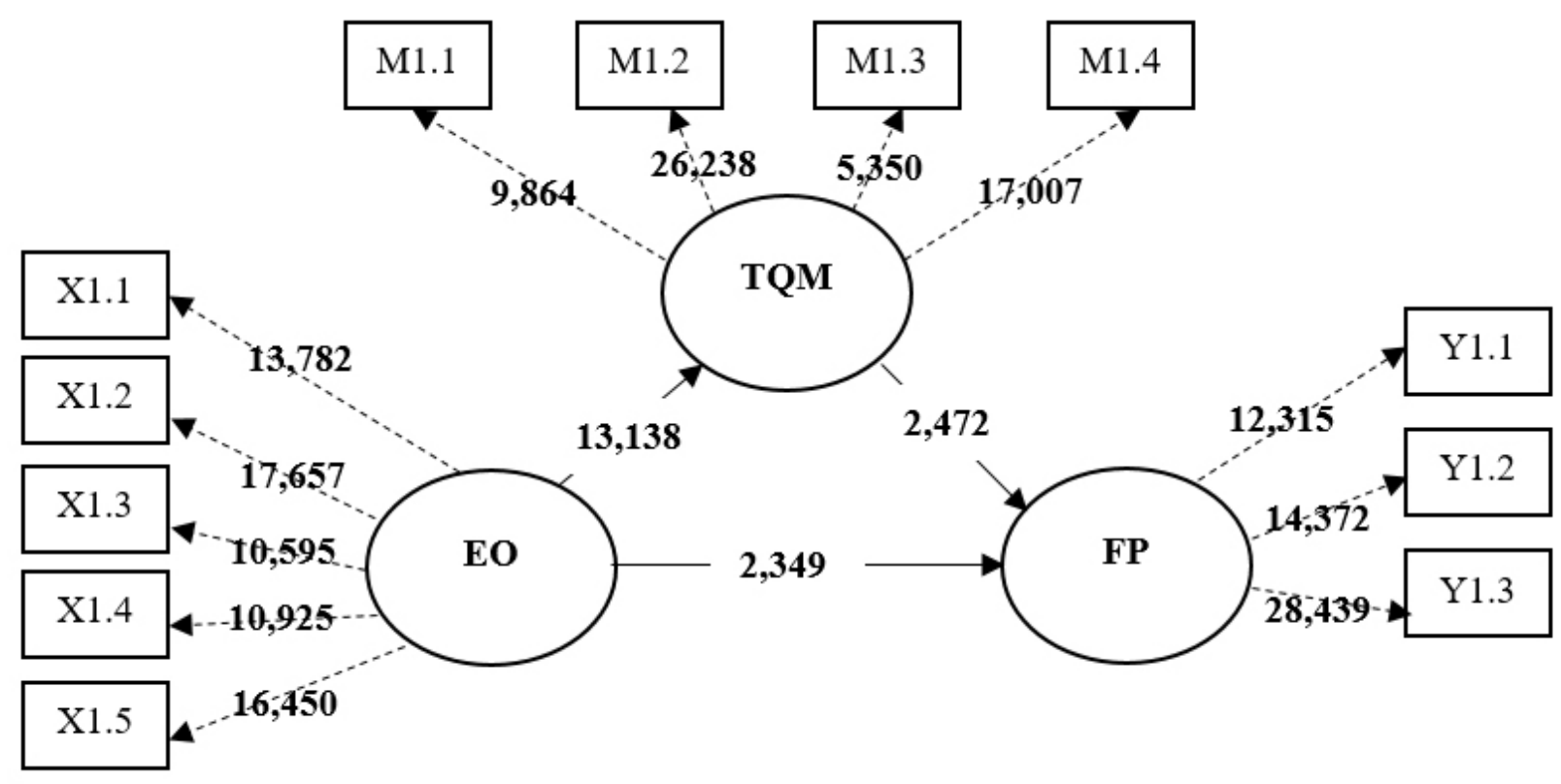

Gambar 2. Partial Least Square Model

Penerapan TQM menemukan banyak hambatan apabila tidak ada EO dalam setiap manajemen perusahaan. Hal ini menunjukkan bahwa EO dan TQM merupakan dua hal yang tidak dapat dipisahkan untuk membuat keunggulan performa perusahaan. Pengaruh Total Quality Management (M) terhadap Firm Performance (Y) pada pengujian inner model ditunjukkan oleh nilai $t$-statistic 2,472 dan P Values 0,014 (t-statistic $>1,96, p$ values $<0,05)$. Hal itu membuktikan bahwa $\mathrm{H}_{2}$ "Total Quality Management berpengaruh terhadap Firm Performance" diterima. Hasil penelitian ini selaras dengan penelitian dari Al-Dhaafri et al. (2016) yang mengatakan adanya pengaruh signifikan antara TQM dengan performa perusahaan. TQM merupakan salah satu metode holistik dalam mencari perbaikan bagi sistem manajemen perusahaan agar dapat menghasilkan performa perusahaan yang unggul. Kualitas merupakan prinsip dasar yang digunakan perusahaan untuk menginisiasi strategi bisnis demi mendapatkan keunggulan (Sutrisno et al. 2019). Perusahaan dengan penerapan TQM cenderung berfokus kepada harapan konsumen. Sehingga untuk dapat mewujudkan hal itu perusahaan harus mampu memiliki sistem manajemen dengan kualitas yang baik (Sutrisno dan Ardyan, 2020). Sistem kualitas manajemen yang baik dalam perusahaan dalam dimulai dari para pekerja yang memiliki inisiatif dalam membangun manajemen internal perusahaan.

Setelah itu, para manajer dalam perusahaan juga harus memperhatikan kebutuhan dari pelanggan perusahaan.
Hal itu dapat dilakukan manajer dengan mempersiapkan database pelanggan perusahaan untuk mengantisipasi permintaan pelanggan di masa mendatang. Para manajer dalam perusahaan juga direkomendasikan untuk dapat menguasai teknik statistika dasar yang berguna untuk menandai penyimpangan yang terjadi pada saat proses operasional perusahaan berjalan. Penelitian menemukan adanya pengaruh Entrepreneurial Orientation (X) terhadap Firm Performance (Y) pada pengujian efek utama yang ditunjukkan oleh nilai $t$-statistic 2,349 dan $P$ Values 0,019 (t-statistic $>1,96, p$ values $<0,05$ ). Hal itu membuktikan bahwa $\mathrm{H}_{3}$ "Entrepreneurial Orientation berpengaruh terhadap Firm Performance" diterima. Hasil penelitian ini selaras dengan penelitian Sahoo dan Yadav (2017) yang mengatakan adanya pengaruh signifikan antara EO dan performa perusahaan. EO merupakan proses yang menjelaskan bagaimana perusahaan membuat strategi yang mendukung tindakan entrepreneur dalam mengambil suatu keputusan. Penerapan EO bagi performa perusahaan dilihat memiliki indikasi yang kuat apabila diterapkan pada industri manufaktur. Perusahaan yang menerapkan EO akan cenderung memonitor lingkungan operasionalnya agar dapat menemukan peluang baru dalam menginisiasi strategi. Sehingga, EO dalam suatu perusahaan akan mendeskripsikan perilaku strategis manajerial yang menunjukkan sejauh mana perusahaan memenangkan persaingan melalui inovasi, toleran terhadap risiko, dan proaktif terhadap peluang pangsa pasar yang ada. 
Peran mediasi dari variabel Total Quality Management pada pengaruh Entrepreneurial Orientation terhadap FirmPerformance ditunjukkanolehnilait-statistic 2,329 dan $P$ Values 0,020 ( $t$-statistic $>1,96, p$ values $<0,05)$. Nilai path coefficient antara Entrepreneurial Orientation (X) dan Firm Performance (Y) yang signifikan menunjukkan bahwa Total Quality Management (M) berpengaruh sebagai partial mediation (Sahoo dan Yadav, 2017). Hasil penelitian ini membuktikan bahwa $\mathrm{H}_{4}$ "Total Quality Management memediasi Entrepreneurial Orientation dan Firm Performance" diterima. Hal ini juga selaras dengan penelitian dari AlDhaafri et al. (2016) yang mengatakan adanya peran mediasi dari TQM pada pengaruh EO dan performa perusahaan. Penerapan EO tidak dapat berjalan dengan baik apabila perusahaan tidak dapat menawarkan pelanggan dengan kualitas dari manajemen maupun produk yang dihasilkan. Hal itu dikarenakan kualitas dari produk akan berdampak pada kepuasan pelanggan. Keberhasilan dari penerapan TQM sangat bergantung pada komitmen dan kepemimpinan dari manajemen puncak perusahaan (Sahoo dan Yadav, 2017). Hasil pembelajaran ini, penerapan EO dan TQM dinilai dapat menjadi landasan bagi suatu perusahaan untuk meningkatkan kinerja perusahaan dan dapat membantu perusahaan mencapai keunggulan kompetitif.

\section{Implikasi Manajerial}

Secara implikasi, penelitian ini menunjukkan bahwa pentingnya bagi suatu perusahaan manufaktur dalam menerapkan EO. Hal itu dikarenakan EO dapat mendorong para pekerja pada perusahaan memiliki sikap entrepreneur dalam menjalankan kegiatan operasional perusahaan. Oleh karena itu, pengelolaan EO dan TQM dalam sebuah perusahaan harus terus dikembangkan, dengan demikian performa perusahaan akan terjaga. Penelitian ini juga memberikan informasi bahwa pentingnya penerapan TQM bagi manajemen perusahaan. TQM memiliki peran untuk menjaga kualitas dari manajemen perusahaan yang nantinya akan berdampak pada kualitas produk dari perusahaan. Sehingga, nantinya output dari perusahaan dapat memuaskan harapan dari pelanggan.

Keterbatasan penelitian ini yaitu sampel memiliki keterbatasan terdiri dari level minimal manajer dalam perusahaan. Namun, karena jumlah manajer yang terbatas pada perusahaan maka sampel dari penelitian ini melibatkan beberapa karyawan yang terjun di bidang manajemen bagian perusahaan. Keterbatasan lain dari penelitian ini merupakan dengan adanya pandemi COVID-19 ini membuat protokol perusahaan menjadi lebih ketat sehingga membuat peneliti kesulitan dalam menghubungi sampel. Kondisi ini menyebabkan nilai respon rate dalam penelitian ini sebesar 64\% (50 responden dari total 78 sampel).

\section{KESIMPULAN DAN SARAN}

\section{Kesimpulan}

Hasil penelitian menunjukkan bahwa perusahaan yang memiliki Entrepreneurial Orientation yang baik akan berdampak pada performa perusahaan mereka. Pada industri manufaktur khususnya sangat penting untuk memperhatikan bagaimana menjaga kualitas dari produk maupun layanan mereka. Sehingga untuk menunjang hal itu memerlukan adanya strategi yang tepat seperti penerapan konsep TQM. Hasil penelitian ini juga membuktikan adanya pengaruh positif antara Entrepreneurial Orientation dengan TQM. Penerapan Entrepreneurial Orientation pada konsep TQM akan membantu perusahaan dalam menciptakan manajemen strategi yang konsisten. Selanjutnya, penelitian ini menunjukkan adanya pengaruh positif antara Total Quality Management dengan performa perusahaan. Penerapan konsep Total Quality Management yang baik tentunya juga akan berdampak pada bagaimana para pekerja perusahaan mampu untuk menciptakan performa produk dengan kualitas yang baik. TQM terbukti memediasi pengaruh antara Entrepeneurial Orientation dan Firm Performance. Hal ini dapat dilihat dari adanya kemampuan perusahaan mengumpulkan sumber daya manusianya (TQM) untuk menyusun strategi yang proaktif demi mengantisipasi permintaan pelanggan di masa mendatang (EO) sehingga perusahaan dapat menjaga kualitas dari produk (firm performance).

\section{Saran}

Peneliti selanjutnya diharapkan mampu meneliti lebih dalam mengenai Total Quality Management seperti membedakan antara soft TQM dan hard TQM dalam penelitian yang dilakukan. Peneliti selanjutnya diharapkan dapat mengaitkan teori lainnya yang berkaitan dengan manajemen perusahaan. Peneliti di masa depan diharapkan untuk dapat meneliti konsep Total Quality Management pada skala perusahaan atau industri yang lebih besar maupun industri yang berbeda 
sehingga diharapkan mampu untuk membantu peneliti di masa depan dapat menemukan insight baru bagi perusahaan yang diteliti.

\section{DAFTAR PUSTAKA}

Al-Dhaafri HS, Al-Swidi AK, Yusoff RZ. 2016. The mediating role of total quality management between the entrepreneurial orientation and the organizational performance. TQM Journal 28(1):89-111. https://doi.org/10.1108/TQM-032014-0033

[BPS] Badan Pusat Statistik. 2019. Produksi kayu bulat oleh perusahaan hak pengusahaan hutan menurut jenis kayu. https://bps.go.id/linkTableDinamis/ view/id/1115

[BPS] Badan Pusat Statistik. 2020. Pertumbuhan ekonomi Indonesia triwulan IV-2019. Www.Bps. Go.Id, 17/02/Th. XXIV, 1-12. https://www.bps. go.id/pressrelease/2020/02/05/1755/ekonomiindonesia-2019-tumbuh-5-02-persen.html

Barney J. 1991. Firmresources and sustained competitive advantage. JournalofManagement 17(1):99-120. https://doi.org/10.1177/014920639101700108

Gupta VK, Batra S. 2016. Entrepreneurial orientation and firm performance in Indian SMEs: Universal and contingency perspectives. Journal Researching Entrepreneurship 34(5):660-682. https://doi.org/10.1177/0266242615577708

Pang C, Wang Q, Li Y, Duan G. 2019. Integrative capability, business model innovation and performance. European Journal of Innovation Management 22(3):541-561. http://dx.doi. org/10.1108/ejim-09-2018-0208

Purwantoro P, Daryanto HK, Djohar S. 2018. Strategi bersaing dan pengukuran kinerja dengan pendekatan resources base view perusahaan komponen otomotif Indonesia. Jurnal Aplikasi Bisnis dan Manajemen 4(2):220-220. http:// dx.doi.org/10.17358/jabm.4.2.220

Rezaei J, Ortt R. 2018. Entrepreneurial orientation and firm performance: The mediating role of functional performances. Management Research Review 41(7):878-900. https://doi.org/10.1108/ MRR-03-2017-0092

Sahoo S, Yadav S. 2017. Entrepreneurial orientation of SMES, total quality management and firm performance. Journal of Manufacturing Technology Management 28(7): 892-912. https://doi.org/https://doi.org/10.1108/JMTM-

\section{4-2017-0064}

Saleh RA, Sweis RJ, Mahmoud Saleh FI. 2018. Investigating the impact of hard total quality management practices on operational performance in manufacturing organizations: Evidence from Jordan. Benchmarking: An International Journal 25(7):2040-2064. https:// doi.org/10.1108/BIJ-05-2016-0074

Salisu Y, Bakar LJA. 2019. Technological capability, relational capability and firms' performance. Revista de Gestão 27(1):79-99. http://dx.doi. org/10.1108/rege-03-2019-0040

Sarstedt M, Ringle CM, Hair JF. 2017. Partial Least SquareStructural Equation Modeling: Handbook of Market Research. Switzerland: Springer. https://doi.org/10.1007/978-3-319-05542-8

Sutrisno TF, Timotius FCW. 2019. Relationship between total quality management element, operational performance and organizational performance in food production SMEs. Journal of Applied Management (JAM) 17(2):285-294. https://doi.org/http://dx.doi.org/10.21776/ ub.jam.2019.017. 02.11

Sutrisno TF, Christian W, Ardyan E. 2020. Achieving organizational performance in food companies: The critical role of leadership and continuous improvement as part of TQM practice. Quality Access to Success 21(177):133-138.

Sutrisno TF, Effendy JA, Prathivi MDG. 2019. Hybrid strategy study: The role of entrepreneurial orientation and total quality management in MSMEs. Jurnal Manajemen dan Kewirausahaan 7(2):124-131.

Teofilus T, Singh SK, Sutrisno TCFW, Kurniawan A. 2020. Analyzing entrepreneurial marketing on innovative performance. Mix: Jurnal Ilmiah Manajemen 10(1):78-90. http://dx.doi. org/10.22441/mix.2020.v10i1.006

Vaitoonkiat E, Charoensukmongkol P. 2020. Interaction effect of entrepreneurial orientation and stakeholder orientation on the business performance of firms in the steel fabrication industry in Thailand. Journal of Entrepreneurship in Emerging Economies 12(4):453-473. https:// doi.org/10.1108/JEEE-05-2019-0072

Vaznyte E, Andries P. 2019. Entrepreneurial orientation and start-ups' external financing. Journal of Business Venturing 34(3):439-458. http://dx.doi. org/10.1016/j.jbusvent.2019.01.006

Utami CW. 2019. The implication of managerial implementation of entrepreneurial marketing 
in business organization. International Journal of Scientific \& Technology Research 8(5):136144.

Utami CW, Ferdiansah M. 2017. Development of knowledge management model in establishing innovation and company performance in UMKM/ SME in Indonesia. European Research
Studies Journal 20(4B):655-665.

Zehir C, Can E, Karaboga T. 2015. Linking entrepreneurial orientation to firm performance : the role of differentiation strategy and innovation performance. Procedia-Social and Behavioral Sciences 210:358-367. https://doi.org/10.1016/j. sbspro.2015.11.381 